\title{
COVID-19 pandemisi ve uyku bozuklukları: COVID-somnia
}

\author{
Handan INÖNÜ \\ KÖSEOĞLU(ID)
}

Makale atıfi: İnönü Köseoğlu H. COVID-19 pandemisi ve uyku bozukluklarl: COVID-somnia. Tuberk Toraks 2021;69(3):387-391.

Yazışma Adresi (Address for Correspondence)

Dr. Handan INÖNÜ KÖSEOĞLU

Tokat Gaziosmanpaşa Üniversitesi Tıp Fakültesi, Göğüs Hastalıkları Anabilim Dalı,

TOKAT - TÜRKIYE

e-mail: handaninonu@gmail.com

OTelif Hakkı 2021 Tüberküloz ve Toraks. Makale metnine

www.tuberktoraks.org web adresinden ulașılabilir.
Tokat Gaziosmanpaşa Üniversitesi Tıp Fakültesi, Göğüs Hastalıkları Anabilim Dalı, Tokat, Türkiye

Department of Chest Diseases, Tokat Gaziosmanpasa University

Faculty of Medicine, Tokat, Turkey

\section{ÖZ}

COVID-19 pandemisi ve uyku bozuklukları: COVID-somnia

Tüm dünyayı etkileyen COVID-19 salgını, kişilerin günlük rutinlerinde ve yaşam tarzında önemli değişikliklere yol açtı. Teması azaltmak için insanlar evlerine kapandı ve sosyalleşme telekomünikasyon yoluyla uzaktan gerçekleşti. Uzun süreli izolasyon, enfekte olma korkusu, belirsizlik, hayal kırıklığı, yetersiz malzeme ve ekonomik kayıp gibi faktörler bireylerin psikolojik durumunu olumsuz etkiledi. Psikososyal stresörler uyku düzenini etkiledi ve uyku kalitesinin kötüleşmesine neden oldu. Tüm bunların sonucunda uyku bozuklukları ortaya çıktı. Pandemi sırasında görülen uyku bozuklukları COVIDsomnia olarak tanımlandı. Bu derlemede, COVID-19 enfeksiyonu uyku ilişkisi ve COVID-19 pandemisinde görülen uyku bozuklukları literatür bilgileri eşliğinde sunuldu.

Anahtar kelimeler: Uyku bozuklukları; insomnia; COVID-19; Koronavirüs; pandemi

\section{ABSTRACT}

COVID-19 pandemic and sleep disorders: COVID-somnia

As a pandemic sweeping over the world, COVID-19 has led to significant changes in daily routines and lifestyle. People closed to their homes to reduce their contact with each other and socialization took place with telecommunication facilities. Moreover, factors like an extended period of isolation, fear of infection, uncertainty, disappointment, insufficient supplies, and economic damage also negatively impacted individuals' psychological wellbeing. Psychosocial stressors affected the pattern of sleep and caused worsening of sleep quality in individuals. As a result of all this, sleep disorders have emerged. Sleep disturbances during pandemic have been referred as COVID-somnia. In this review, the relationship of COVID-19 infection and sleep, and sleep disorders during COVID-19 pandemic are presented in the light of the literature.

Key words: Sleep disorders; insomnia; COVID-19; coronavirus; pandemic 


\section{Giriş}

COVID-19 pandemisinin ilanının üzerinden bir yılı aşkın bir süre geçti. COVID-19 salgını sağlık, sosyal, ekonomik boyutlarıyla tüm dünyada birçok izler bıraktı, bırakmaya devam ediyor. Teması azaltmak için insanlar evlerine hapsoldu, telekomünikasyon yoluyla iletişim kurulmaya çalışıldı, sosyalleşme uzaktan gerçekleşti. Bu önemli boyutta bir davranış değişikliğiydi. Evde kapalı olma hali fiziksel aktivite, yeme alışkanlıkları, elektronik cihaz kullanımı bakımından kişilerin rutin hayatını değiştirdi. Bu faktörler uyku alışkanlıklarında ve uyku kalitesinde değişikliğe neden oldu. Küresel topluluklar arasında hem nitelik hem de nicelik açısından karakteristik uyku değişiklikleri ve artan uyku bozuklukları gözlemlendi. Karantina sürecinde "chronotype" olarak tanımlanan kişinin 24 saatlik uyku-uyanıklık döngüsündeki değişim, uyku düzeninin bozulmasında etkili oldu. COVID-19 pandemisi sırasında görülen uyku bozukluklarını tanımlamak için "COVID-Somnia" terimi kullanıldı (1). Bu derleme yazısında, COVID-19 enfeksiyonu-uyku ilişkisi ve COVID-19 pandemisinde görülen uyku bozuklukları literatür bilgileri eşliğinde sunulmuştur.

Uyku, fiziksel ve zihinsel sağlığı korumak ve iyi bir yaşam kalitesi için önemli bir fizyolojik aktivitedir. Normal uyku döngüsündeki bozulma yetersiz uykuya ve uzun süreli uyanıklığa yol açarak uykusuzluk, kabus görme, gündüz dengesizliği ve yorgunluğa neden olur (2). Uyku bozukluklarının gelişimindeki potansiyel risk faktörleri arasında şiddetli stresli durumlar, depresyon, anksiyete, travma, düşük sosyoekonomik durum, kentsel yaşam, teknoloji kullanımı ve sosyal medya yer almaktadır (3). Uyku tepkiselliği (reaktivitesi), insanların stresli durumlara farklı tepkiler vermesidir. Uyku tepkisi yüksek olanlarda uyku bozuklukları daha çok gelişmektedir (1). Son araştırmalar uyku bozukluklarının her dört yetişkinden birini etkilediğini göstermiştir (4). Dünya genelinde, uyku bozuklukları ve ruhsal bozukluklarda artan bir yük söz konusudur (5).

COVID-19 salgını ve alınan karantina önlemleri insanların ruh sağlığı üzerinde ağır bir etki yaratmıştır. Uzun süreli izolasyon, enfeksiyon korkusu, belirsizlik, hayal kırıklığı, yorgunluk, damgalanma, hastaIıkla ilgili yetersiz veri ve bilgiler, yetersiz malzeme, ekonomik problemler, işsizlik, sosyal desteğin azlığı/ yokluğu gibi faktörler bireylerin psikolojik durumunu olumsuz etkileyen faktörlerdir (6). Nitekim, tarihsel olarak SARS enfeksiyonundaki karantina süreci de anksiyete, depresyon, panik, sinirlilik, somatik bozukluk ve uykusuzluk ile ilişkilendirilmiştir $(7,8)$. Geniş kapsamlı bir çalışmada, COVID-19 salgını sırasında genel popülasyonda stres, anksiyete ve depresif semptomların yaygınlığı sırasıyla \%29,6, \%31,9 ve $\% 33,7$ olarak bulunmuştur (9). Yakın zamanda yapılan bir araşıırma, COVID-19 ile ilgili kaygının uykusuzluk şiddeti ve intihar düşüncesiyle ilişki gösterdiğini ortaya koymuştur (10).

Enfeksiyonlar ile uyku arasındaki etkileşime bakıldığında; farklı enfeksiyonların uyku üzerinde farklı etkilerinin olduğu, bazı enfeksiyonların uyku miktarını artırırken, bazılarının azalttığı görülmüştür. Sistemik enfeksiyonla ilişkili enflamatuvar mediatörlerde artışın, belki de enerji tasarrufu sağlamak ve enfeksiyona karşı koymak çabasıyla NREM uykusunun miktarını ve toplam uyku süresini artırdığı düşünülmektedir. Bazı enfeksiyonlar da, bağışıklık sistemi üzerine olumsuz etki ederek uyku miktarını azaltır (11). COVID-19 enfeksiyonuna neden olan SARSCoV-2 virüsü nazal ve hematojen yolla merkezi sinir sistemine ulaşabilmektedir. Ayrıca, vasküler alanda bulunan enflamatuvar mediyatörler kan-beyin bariyerinin geçirgenliğini arttırarak, viral proteinlerin merkezi sinir sistemine girişini kolaylaştırmaktadır. Bunu, mikroglial aktivasyon, nöronal enflamasyon, oligodendrositlerin ve astrositlerin upregülasyonu, mikroanjiyopati ve nöronal hasar gibi beyinde bir dizi yapısal ve fonksiyonel değişiklik takip eder. SARS$\mathrm{CoV}-2$ virüsü, beyinde prefrontal korteks, bazal ganglionlar ve hipotalamusu etkiler ki bu bölgeler uykunun regülasyonunda önemlidir. Bu nedenle, COVID19 pandemisinde görülen uyku bozuklukları prevalansının yaygınlığını, kişilerin yaşadığı sosyal ve emosyonel stresör faktörlerin yanı sıra, asemptomatik viral enfeksiyona sekonder merkezi sinir sistemi etkilenmesine bağlamak yanlış olmayacaktır (12). Öte yandan uyku, hücresel ve hümoral bağışıklığın düzenlenmesinde önemli bir rol oynar ve uyku yoksunluğu bağışıklık yanıtını azaltır. Bu nedenle, yeterli miktarda optimum kalitede uyku, enfeksiyonla mücadele için önemli bir faktördür. Sonuçta uyku ve COVID-19 enfeksiyonu arasında çift yönlü bir ilişkinin olduğunu söylemek mümkündür (11).

Pandemi süresince yaşlılarda COVID-19 enfeksiyonu ağır seyretmiş̧tir. Bunda yaşılıarda eşlik eden sistemik komorbid hastalıkların fazla olması, bağışıklık yanıtının zayıf olmasının yanı sıra, yaşlılardaki uyku yapısındaki değişimlerin de bu seyire katkıda bulunduğu 
belirtilmektedir. Yaşlılarda COVID-19 enfeksiyonuna yatkınlık ve ağır seyir nedenlerinin araştıııldığı bir çalışmada sirkadiyen ritmin yaşlanması, uyku-uyanıklık şiftinin ilerlemesi gibi uykuyu kötüleştiren çeşitli faktörlerin önemine değinilmiş, antioksidan ve immünmodülatör özellikleriyle bilinen melatonin ritminin ve miktarının azalmasının, yaşılıarda COVID-19 enfeksiyonuna duyarlılığın artmasına katkıda bulunabileceği ileri sürülmüştür (13).

COVID-somnia (Coronasomnia); pandemi sırasında görülen uyku bozukluklarını tanımlamak için kullanılan bir terimdir (1). COVID-19 pandemisi süresince, uyku bozukluklarını incelemek amacıyla birçok çalışma yapılmıştır. Konuyla ilgili yapılan ilk sistematik derlemede, çoğu kesitsel çalışma ve online anket uygulaması şeklinde gerçekleştirilen, birçok verinin Çin ve Amerika'dan elde edildiği, toplum ve hastane verilerinin kaydedildiği 78 makale değerlendirilmiş; uyku bozukluğu prevalansı \%2,3-76,6 arasında bulunmuştur (14). Prevalans aralığının bu kadar geniş olması, coğrafi bölgeler arasında farklı sonuçlar elde edilmesine bağlanmıştır. İnsomnia prevalansı Amerika Birleşik Devletleri'nde \%20-41, Çinli iş̧̧ilerde \%2,3, Çin'de ön saflarda çalışan sağlık personelinde \%58, İtalya'da \%37,6-57 olarak tespit edilmiştir. Bu kapsamlı araştırma en sık görülen uyku bozukluklarının; uykusuzluk (insomnia), anksiyete ve depresyon olduğunu ortaya koymuştur. Yaş, cinsiyet, eğitim düzeyi, fiziksel ve mental sağlık, COVID-19 ilişkili stresör faktörler, meslek (özellikle sağlık çalışanı olmak) uyku bozukluğu ile ilişkili faktörler olarak tespit edilmiştir. Çalışmaların \%20'sinde insomnia kadınlarda sık tespit edilmiş, pandemi süresince sadece yaşııların değil gençlerin de uyumakta güçlük çektiği dikkat çekmiştir. Eğitim düzeyi yüksek olanlarda uyku bozukluğunun sık izlendiği, sosyal desteği olmayan, tek başına yalnız yaşayan bireylerin daha çok uykusuzluk yaşadığı ve düşük uyku kalitesine sahip olduğu gösterilmiştir. Önceden kronik hastalığı olanlarda insomnia sık görülürken ve psikiyatrik hastalığı olan hastalarda var olan insomnianın daha da belirginleştiği tespit edilmiştir. Çalışmada; stres, anksiyete, depresyon ve yorgunluk kötü uyku ile ilişkili faktörler olarak bulunmuştur. Sağlık çalışanlarında insomnia daha sık, uyku kalitesi daha kötü tespit edilirken, ön safta çalışanlarda bu bozukluklar daha fazla oranda bulunmuştur. Salgının geçim kaynakları üzerindeki etkisinden endişe duyarak, düşük gelirli kişilerde daha fazla uyku bozukluğu riski gözlenmiştir. COVID-19'a özgü uyku ile ilişkili faktörler;
COVID-19'a yakalanmış hastalarda hastalıkla ilgili endişeler, pandemiye bağlı belirsizlik, testin bulunmaması, maske takma gibi kontrol önlemlerine karşı olumsuz tutum şeklinde sıralanmıştır. Farklı bir çalışmada 843 katılımcı anketle incelenmiş; katılımcıların $\% 69,4^{\prime} \ddot{u}$ uyku düzeninde bir değiş̧iklik olduğunu, yarısından azı $(\% 44,7)$ dinlendirici bir uykuya sahip olduğunu, \%45,6'sı karantina öncesine göre daha uykulu olduğunu bildirmişlerdir (15). Uykuya özgü sık bildirilen değişimler; uyku kesintisi (bölünmüş uyku) $(\% 42,3)$, istem dışı uykuya dalma $(\% 35,2)$, uykuya dalmada zorluk $(\% 30,9)$, geç yatma saatleri (\%30) şeklinde bulunmuştur. COVID-19 şüphesi olan katılımcılar daha fazla kabus gördüğünü belirtmişlerdir. Olguların \%65,2'si zihinsel sağlıklarının etkilediğini, \%25,9'u karantina sürecinde daha fazla alkol aldığını ifade etmiştir. Uykuya dalma güçlüğü, bozulmuş uyku, gündüz uykululuk ve kabuslar gibi değişikliklerle, ruh sağlığı üzerindeki etkiler güçlü bir şekilde ilişkilendirilmiştir. On üç ülkeden, 54,231 katılımcıyı içeren bir meta-analizde, Epworth "Sleepiness Scale, Pittsburg Sleep Quality Index, Insomnia Severity Index, Athens Insomnia Scale" gibi ölçekler kullanılarak uyku yapısı değerlendirilmiş; uyku bozukluğu prevalansının genel popülasyonda \%32,3; sağlık çalışanlarında \%36; COVID enfekte hastalarda \%74,8 oranında olduğu ortaya konulmuştur (16). Çalışmalarda COVID-19 hastalarında yaygın görülen uyku problemlerinin, hastalığın semptomları olan öksürük, ateş, solunum sıkıntısı ile ilişkili olabileceği, yine hastalığa bağlı fiziksel ağrı ve ilaç yan etkilerinin de uyku problemlerine neden olabileceği vurgusu yapılmıştır $(17,18)$. Klinik deneyimler, çok sayıda hastada COVID-19'dan iyileştikten sonra bile uyku bozukluğunun devam ettiğini göstermektedir. COVID-19 salgınında doktorlarda görülen uyku bozukluklarını incelemek amacıyla; Suudi Arabistan Krallığı'nın batısındaki Mekke, Cidde ve Taif şehirlerindeki Suudi doktorlarda Mayıs-Ağustos 2020 tarihleri arasında yapılan bir çalışmada uyku kalitesini değerlendirmek için "Pittsburg Sleep Quality Index" ölçeğinden beş madde ele alınarak inceleme yapılmış; son bir ay içindeki subjektif uyku kalitesi, 30 dakika içinde uykuya başlama zorluğu, uykudan kolay uyanma ve sabah erken uyanma, uyku ilacı kullanımı ve uyku süresi değerlendirilmiştir (19). Aşağıda tanımlanan beş özelliğin hepsinin varlığı durumunda uyku "çok kaliteli" olarak tanımlanmıştır: (a) Yatakta geçirilen uyku süresinin, toplam sürenin en az \%85'i olması, (b) 30 dakika veya daha kısa sürede uykuya dalmak, (c) yedi saat veya daha fazla 
uyumak, (d) kalktıktan sonra 20 dakika içinde tekrar uykuya dalmak, (e) gecede birden fazla uyanmamak -beş dakikadan daha uzun süre-. Katılımcılardan uyku kalitelerini "çok iyi", "oldukça iyi", "oldukça kötü" ve "çok kötü" olarak derecelendirmeleri istenmiştir. Çalışmada uyku bozukluğu prevalansı \%43,9 bulunmuş, uyku bozukluklarının farklı sosyodemografik ve işle ilgili özelliklerle ilişkisi karşılaştırıldığında yaş, görev ve uzmanlık ile anlamlı bir ilişki gözlenmiştir. Uyku bozukluğu oranı 31-40 yaş grubundaki (\%63) doktorlarda diğer yaş gruplarına göre daha fazla $(p=0,02)$, konsültan hekimlerde $(\% 53,1)$ ve asistanlarda $(\% 49,6)$ daha yüksek $(p<0,01)$ tespit edilmiştir. Yazarlar, genç hekimlerin ilk kez böyle bir salgın yaşıyor olmalarının ve hastanede uyumak zorunda bulunmalarının uyku yoksunluğuna yol açabileceği yönünde çıkarım yapmışlardır. Uyku bozukluğunun yaygınlığı farklı uzmanlık alanlarına göre incelendiğinde; acil tıp doktorları, anestezistler, laboratuvar (patoloji/mikrobiyoloji) uzmanları ve diş hekimleri, diğer uzmanlık dallarına göre en yüksek prevalansa $(\% 66,7)$ sahip bulunmuştur $(p=0,024)$. Kadın doktorlarda erkeklere göre uyku kalitesinin daha kötü olduğu, uyku hapı kullananların önemli bir bölümünü dahiliye ve cerrahi branş hekimlerinin oluşturduğu vurgulanmıştır. Sağlık çalışanlarının $\% 23,4^{\prime}$ ü uyku kalitesini çok iyi, $\% 60$ 'ı orta derecede iyi, \%3,5'i çok kötü olarak tanımlanmıştır.

Pandemide artan iş talepleri, yetersiz molalar ve stres nedeniyle bozulmuş uyku, sağlık çalışanlarında klinik tükenmişliğe neden olabilmektedir (20). Bazı çalışanların enfekte olma korkusuyla işten uzak durması tıbbi personel eksikliğiyle sonuçlanmaktadır (21). Uyku yoksunluğu yaşayan hekimlerde kognitif ve motor fonksiyonlarda meydana gelen bozulma, tıbbi hata yapma riskini artırırken, zayıf konsantrasyon ve dikkat eksikliği bireylerin virüsle enfekte olma riskini artırmaktadır (22-24).

Sonuç olarak, COVID-19 enfeksiyonu ile uyku bozuklukları arasında iki yönlü bir ilişkinin olduğu görülmektedir. Uyku bozukluklarının optimal yönetimi, pandemi sırasında enfeksiyona yakalanma riskini azaltmanın yanı sıra, COVID-19'a bağlı gelişebilecek olumsuz sağ ıı sonuçlarını azaltmak için de önemlidir. Bu nedenledir ki pandemide hem genel popülasyonda hem de sağlık çalışanlarında uyku kalitesinin iyileştirilmesi önemlidir. Uyku kalitesini iyileştirebilecek yöntemler arasında; sosyal ve idari destek, gevşeme teknikleri ve iyileşmeye izin veren makul çalışma programları sayılabilir.

\section{KAYNAKLAR}

1. Gupta R, Pandi-Perumal SR. COVID-Somnia: How the Pandemic Affects Sleep/Wake Regulation and How to Deal with it? Sleep Vigil 2020; 4: 51-3.

2. Otsuka Y, Kaneita Y, Itani O, Nakagome S, Jike M, Ohida T. Relationship between stress coping and sleep disorders among the general Japanese population: A nationwide representative survey. Sleep Med 2017; 37: 38-45.

3. Chattu VK, Manzar D, Soosanna Kumary S, Burman $D$, Spence DW, Pandi-Perumal SR. The Global Problem of Insufficient Sleep and Its Serious Public Health Implications. Healthcare 2019; 7(1): 1-16.

4. Seng EK, Cervoni C, Lawson IL, Oken T, Sheldon S, McKee MD. The Burden of Sleep Problems: A Pilot Observational Study in an Ethnically Diverse Urban Primary Care Setting. J Prim Care Community Health 2016; 7(4): 276-80.

5. Rajkumar RP. COVID-19 and mental health: A review of the existing literature. Asian J Psychiatr 2020; 52: 102066.

6. Brooks SK, Webster RK, Smith LE, Woodland L, Wessely S, Greenberg N, et al. The psychological impact of quarantine and how to reduce it: rapid review of the evidence. Lancet 2020; 395: 912-20.

7. DiGiovanni C, Conley J, Chiu D, Zaborski J. Factors influencing compliance with quarantine in Toronto during the 2003 SARS outbreak. Biosecur Bioterror 2004; 2(4): 265 72.

8. Hawryluck L, Gold WL, Robinson S, Pogorski S, Galea S, Styra R. SARS control and psychological effects of quarantine, Toronto, Canada. Emerg Infect Dis 2004; 10(7): 1206-12.

9. Salari N, Hosseinian-Far A, Jalali $R$, Vaisi-Raygani A, Rasoulpoor S,Mohammad $M$, et al. Prevalence of stress, anxiety, depression among the general population during the COVID-19 pandemic: a systematic review and meta-analysis. Global Health 2020; 16(1): 57.

10. Killgore WDS, Cloonan SA, Taylor EC, Fernandez F, Grandner MA, Dailey NS. Suicidal ideation during the COVID-19 pandemic: the role of insomnia. Psychiatry Res 2020; 290: 113134.

11. Ibarra-Coronado EG, Pantaleón-Martínez AM, VelazquézMoctezuma J, Prospéro-García O, Méndez-Díaz M, PérezTapia $M$, et al. The Bidirectional Relationship between Sleep and Immunity against Infections. I Immunol Res 2015; 2015: 678164

12. Banerjee $D$, Viswanath $B$. Neuropsychiatric manifestations of COVID-19 and possible pathogenic mechanisms: insights from other coronaviruses. Asian J Psychiatry 2020; 54: 102350.

13. Cardinali DP, Brown GM, Reiter RJ, Pandi-Perumal SR. Elderly as a high-risk group during COVID-19 pandemic: effect of circadian misalignment, sleep dysregulation and melatonin administration. Sleep Vigil 2020; 26(1): 1-7. 
14. Tasnim S, Rahman M, Pawar P, Chi X, Yu Q, Zou L, et al. Epidemiology of sleep disorders during COVID-19 pandemic: A systematic scoping review. medRxiv 2020.05.17.20104794; doi:10.1101/2020.05.17.20104794

15. Carbonell LP, Meurling $\mathrm{Il}$, Wassermann $D$, Gnon Vi, Leschzine G, Weighall $A$, et al. Impact of the novel coronavirus (COVID-19) pandemic on sleep. J Thorac Dis 2020; 12(2): S163-S175.

16. Jahrami H, BaHammam AS, Bragazzi NL, Saif Z, Faris MA, Vitiello MV. Sleep problems during the COVID-19 pandemic by population: a systematic review and meta-analysis. J Clin Sleep Med 2021; 17(2): 1-15.

17. Ferrando $M$, Bagnasco D, Roustan V, Canonica GW, Braido F, Baiardini I. Sleep complaints and sleep breathing disorders in upper and lower obstructive lung diseases. J Thorac Dis 2016; 8(8): E716-E725.

18. Shi L, Lu ZA, Que JY, Huang XL, Liu L, Ran MS, et al. Prevalence of and risk factors associated with mental health symptoms among the general population in China during the coronavirus disease 2019 pandemic. JAMA Netw Open 2020; 3(7): e2014053.
19. Alnofaiey $Y H$, Alshehri $H A$, Alosaimi $M M$, Alswat $S H$ Alswat RH, Alhulayfi RF, et al. Sleep disturbances among physicians during COVID-19 pandemic. BMC Res Notes 2020; 13: 493 .

20. Söderström $M$, Jeding $K$, Ekstedt $M$, Perski A, Akerstedt $T$. Insufficient sleep predicts clinical burnout. J Occup Health Psychol 2012; 17(2): 175-83.

21. Urooj U, Ansari A, Siraj A, Khan S, Tariq H. Expectations, fears and perceptions of doctors during Covid-19 pandemic. Pak J Med Sci 2020; 36: S37-42.

22. Fletcher KE, Underwood W, Davis SQ, Mangrulkar RS, McMahon LF Jr, Saint S, et al. Effects of work hour reduction on residents' lives: a systematic review. JAMA 2005; 294: 1088-100.

23. Smith JW, Denny WF, Witzke DB. Emotional impairment in internal medicine house staff. Results of a national survey. JAMA 1986; 255(9): 1155-8.

24. Medic G, Wille M, Hemels ME. Short- and long-term health consequences of sleep disruption. Nat Sci Sleep 2017; 9: 151-61. 